\title{
Polymerization of Nitrogen in Nitrogen-Fluorine Compounds Under Pressure
}

Jie Zhang, ${ }^{1}$ Caoping Niu, ${ }^{1}$ Hanxing Zhang, ${ }^{1}$ Jing Zhao, ${ }^{1}$ Xianlong Wang, ${ }^{1, \ddagger}$ Zhi Zeng, ${ }^{1, \dagger}$

${ }^{1}$ Key Laboratory of Materials Physics, Institute of Solid State Physics, HFIPS, Chinese Academy of Sciences, Hefei 230031, China

‡xlwang@theory.issp.ac.cn

${ }^{\dagger}$ zzeng@theory.issp.ac.cn 
TABLE S1: Structural parameters of $\mathrm{NF}_{3}, \mathrm{NF}_{5}$ and $\mathrm{N}_{6} \mathrm{~F}$ compounds.

\begin{tabular}{|c|c|c|c|c|}
\hline & Space group & Lattice parameters $\left(\AA,^{\circ}\right)$ & Atom & Wyckoff positions \\
\hline \multirow{3}{*}{$\begin{array}{c}\mathrm{NF}_{3} \\
(0 \mathrm{GPa})\end{array}$} & \multirow[t]{3}{*}{ Pnma-I } & $a=6.263$ & $\mathrm{~N}$ & $4 c(0.54372,0.25000,-0.07693)$ \\
\hline & & $b=7.372$ & $\mathrm{~F}$ & $4 c(0.70845,0.25000,0.12633)$ \\
\hline & & $c=4.640$ & $\mathrm{~F}$ & $8 d(0.39971,0.60269,0.25155)$ \\
\hline \multirow{3}{*}{$\begin{array}{c}\mathrm{NF}_{3} \\
(20 \mathrm{GPa})\end{array}$} & \multirow[t]{3}{*}{ Pnma-II } & $a=5.508$ & $\mathrm{~N}$ & $4 c(0.21389,0.25000,0.60506)$ \\
\hline & & $b=6.457$ & $\mathrm{~F}$ & $4 c(0.53023,0.25000,0.12960)$ \\
\hline & & $c=3.976$ & $\mathrm{~F}$ & $8 d(0.14902,0.08388,0.80582)$ \\
\hline \multirow{4}{*}{$\begin{array}{c}\mathrm{NF}_{3} \\
(60 \mathrm{GPa})\end{array}$} & \multirow[t]{4}{*}{$P 2_{1} 2_{1} 2_{1}$} & $a=5.929$ & $\mathrm{~N}$ & $4 a(0.30107,0.79102,0.46116)$ \\
\hline & & $b=7.089$ & $\mathrm{~F}$ & $4 a(0.29454,0.61954,0.23362)$ \\
\hline & & $c=2.653$ & $\mathrm{~F}$ & $4 a(0.12702,0.88552,0.23197)$ \\
\hline & & & $\mathrm{F}$ & $4 a(0.48203,0.87007,0.23790)$ \\
\hline \multirow{6}{*}{$\begin{array}{c}\mathrm{NF}_{5} \\
(0 \mathrm{GPa})\end{array}$} & \multirow[t]{6}{*}{$P 1$} & $a=4.618$ & $\mathrm{~N}$ & $1 a(-0.01630,-0.02720,0.89549)$ \\
\hline & & $b=4.635$ & $\mathrm{~F}$ & $1 a(0.31571,0.30426,0.63879)$ \\
\hline & & $c=4.703$ & $\mathrm{~F}$ & $1 a(0.72439,0.10079,0.09801)$ \\
\hline & & $\alpha=70.27$ & $\mathrm{~F}$ & $1 a(0.85450,0.84242,0.75279)$ \\
\hline & & $\beta=70.18$ & $\mathrm{~F}$ & $1 a(0.11368,0.71560,0.09722)$ \\
\hline & & $\gamma=74.36$ & $\mathrm{~F}$ & $1 a(0.53741,0.52441,0.49707)$ \\
\hline \multirow{4}{*}{$\begin{array}{c}\mathrm{NF}_{5} \\
(20 \mathrm{GPa})\end{array}$} & \multirow[t]{4}{*}{$R 3 m$} & $a=4.630$ & $\mathrm{~N}$ & $3 a(0.00000,0.00000,0.89318)$ \\
\hline & & $c=8.468$ & $\mathrm{~F}$ & $9 b(0.82102,0.17898,0.28359)$ \\
\hline & & $\gamma=120$ & $\mathrm{~F}$ & $3 a(0.00000,0.00000,0.72951)$ \\
\hline & & & $\mathrm{F}$ & $3 a(0.00000,0.00000,0.48548)$ \\
\hline \multirow{6}{*}{$\begin{array}{c}\mathrm{NF}_{5} \\
(100 \mathrm{GPa})\end{array}$} & \multirow[t]{6}{*}{$I 4 / m$} & $a=4.909$ & $\mathrm{~N}$ & $4 d(0.00000,0.50000,0.25000)$ \\
\hline & & $c=8.995$ & $\mathrm{~N}$ & $2 b(0.00000,0.00000,0.50000)$ \\
\hline & & & $\mathrm{F}$ & $8 h(0.78025,0.61188,0.00000)$ \\
\hline & & & $\mathrm{F}$ & $16 i(-0.08065,0.30247,0.16522)$ \\
\hline & & & $\mathrm{F}$ & $4 e(0.00000,0.00000,0.66642)$ \\
\hline & & & $\mathrm{F}$ & $2 a(0.00000,0.00000,0.00000)$ \\
\hline $\mathrm{NF}_{5}$ & \multirow[t]{2}{*}{$P 4 / n$} & $a=4.584$ & $\mathrm{~N}$ & $2 a(0.25000,0.75000,0.00000)$ \\
\hline$(200 \mathrm{GPa})$ & & $c=5.763$ & $\mathrm{~N}$ & $2 c(0.25000,0.25000,0.38798)$ \\
\hline
\end{tabular}




\begin{tabular}{c|c|c|c|c|c} 
& & & $\mathrm{F}$ & $2 c(0.25000,0.25000,0.63075)$ \\
& & $\mathrm{F}$ & $2 c(0.25000,0.25000,0.12252)$ \\
& & & $\mathrm{F}$ & $8 g(0.34221,0.54808,0.87179)$ \\
\hline $\mathrm{N}_{6} \mathrm{~F}$ & $R-3 c$ & $a=5.876$ & $\mathrm{~F}$ & $8 g(0.65447,0.45543,0.62359)$ \\
\hline$(200 \mathrm{GPa})$ & $c=6.431$ & $\mathrm{~F}$ & $36 f(0.43761,-0.07881,0.16567)$ \\
& & $\gamma=120$ & & \\
\hline \hline
\end{tabular}




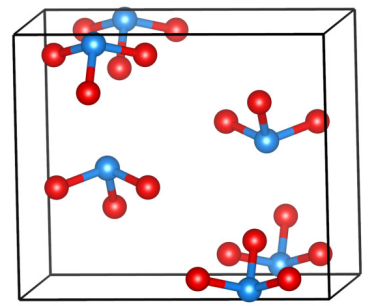

Pnma-I

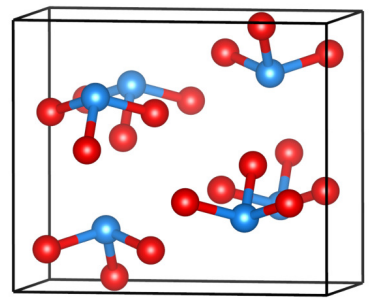

Pnma-II

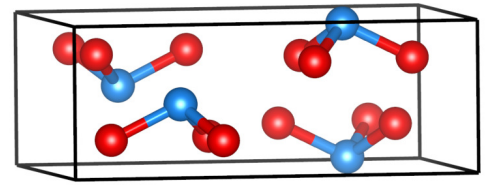

$\mathrm{P} 2{ }_{1} 2_{1} 2_{1}$

FIG. S1. Crystal structures of the $\mathrm{NF}_{3}$ compound. The blue and red balls represent nitrogen and fluorine atoms, respectively. The $\mathrm{NF}_{3}$ molecule configuration is maintained in above three structures.

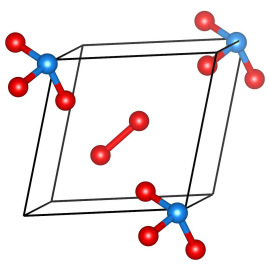

P1

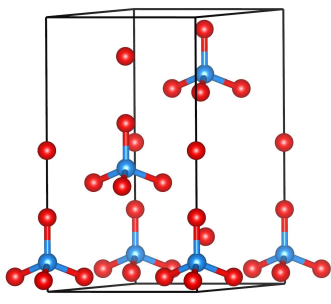

$\mathrm{R} 3 \mathrm{~m}$

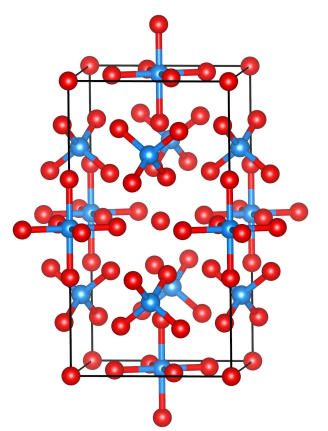

$\mathrm{I} 4 / \mathrm{m}$

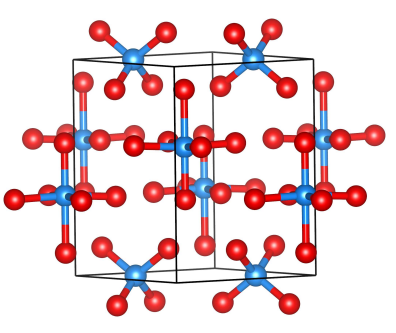

$\mathrm{P} 4 / \mathrm{n}$

FIG. S2. Crystal structures of the $\mathrm{NF}_{5}$ compound. The blue and red balls represent nitrogen and fluorine atoms, respectively. $\mathrm{NF}_{4}$ units are formed in the $R 3 m$ structure, while $\mathrm{NF}_{6}$ units emerge in the $I 4 / m$ and $P 4 / n$ phases with increasing pressure. 

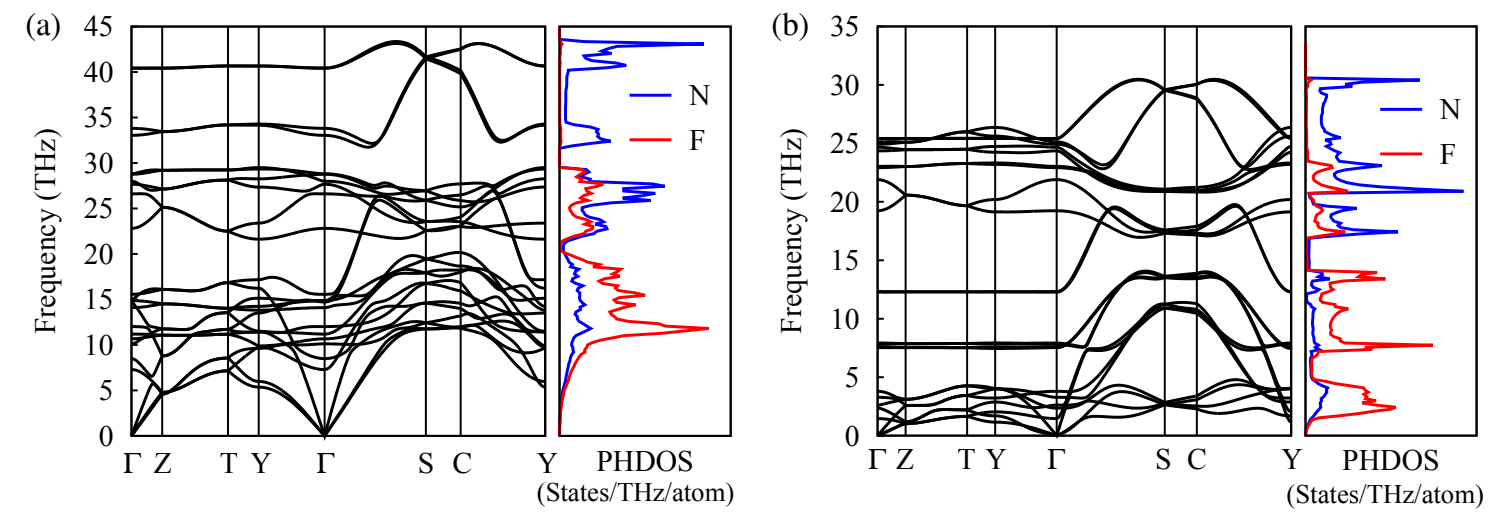

FIG. S3. The phonon spectra and phonon density of states (PHDOS) of the NF-Cmca crystal using the PHONOPY code at $120 \mathrm{GPa}$ (a) and $0 \mathrm{GPa}$ (b). The van der Waals (vdW) interaction correction is considered by using the optB86b-vdw method at $0 \mathrm{GPa}$.

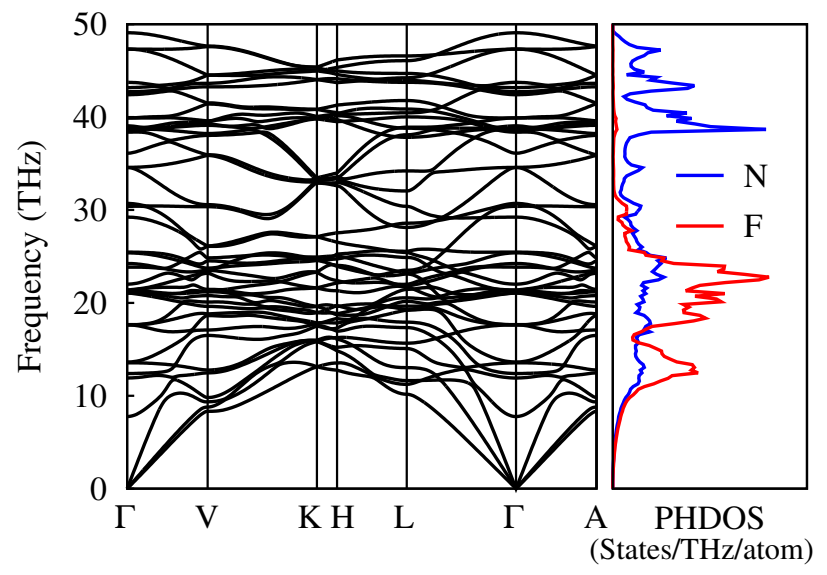

FIG. S4. The phonon spectra and PHDOS of the $\mathrm{N}_{6} \mathrm{~F}-C 2 / c$ crystal using the PHONOPY code at $200 \mathrm{GPa}$. 

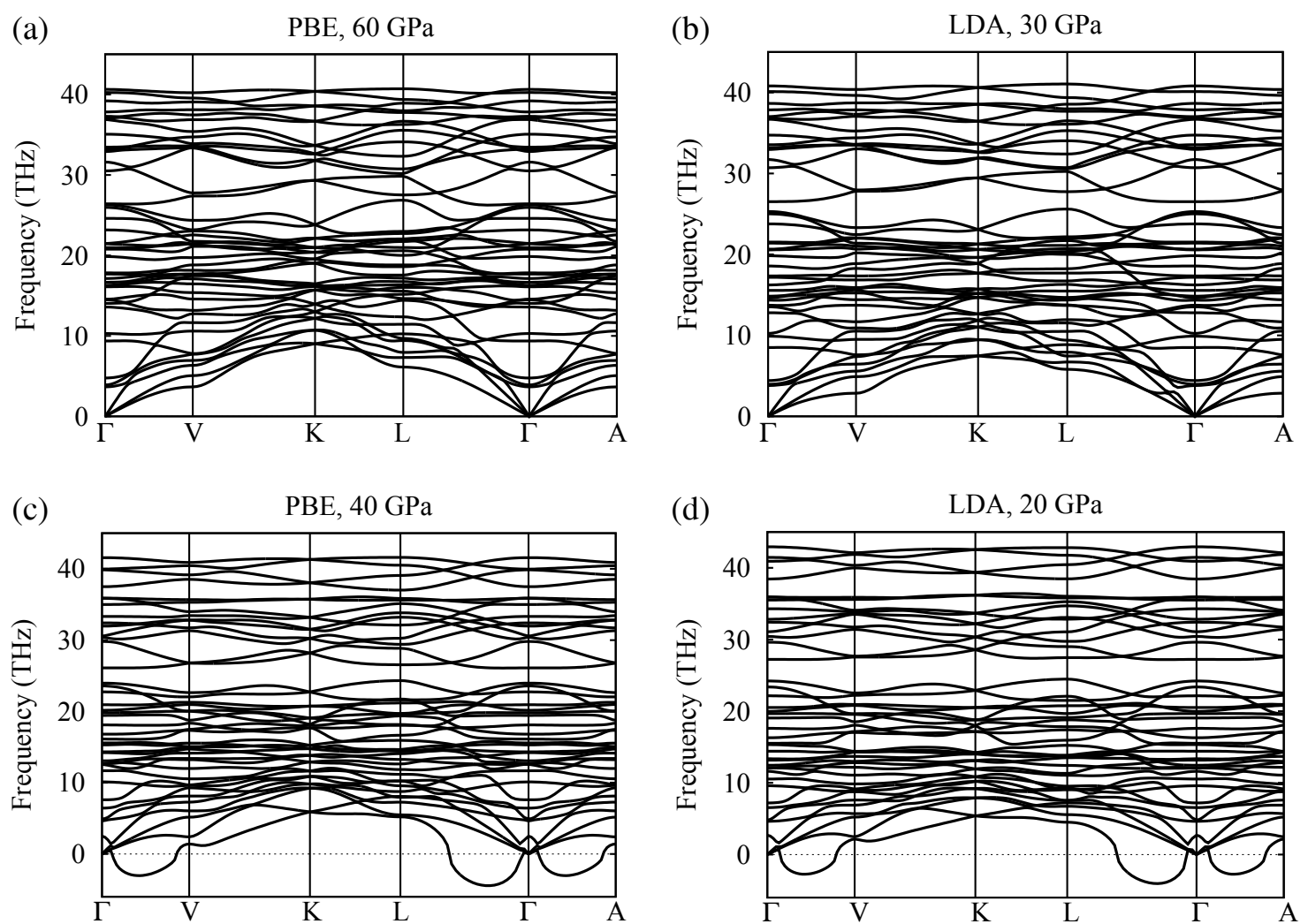

FIG. S5. The calculated phonon spectra of the $\mathrm{N}_{6} \mathrm{~F}-C 2 / c$ crystal using the Quantum ESPRESSO code at $60 \mathrm{GPa}$ with PBE functional (a), at $30 \mathrm{GPa}$ with LDA functional (b), at $40 \mathrm{GPa}$ with PBE functional (c), and at $20 \mathrm{GPa}$ with LDA functional (d). 